\title{
Effect of Organic Photosensitizers on the Antimicrobial Property of Polyurethane coated Leather
}

\author{
Kyung Wha $\mathrm{Oh}^{1{ }^{1 \dagger}}$ and Ki Sub $\mathrm{Lim}^{2)}$ \\ ${ }^{1)}$ Dept. of Home Economics Education, Chung-Ang University; Seoul, Korea \\ ${ }^{2)}$ Technical Textile Technology Center, Korea Institute of Industrial Technology; Ansan, Korea
}

\begin{abstract}
Cow leather coated with polyurethane film that contains various organic photosensitizers was investigated to demonstrate the antimicrobial properties in the application of the material to protective clothing and home appliances. To prepare the antimicrobial coating on leather surfaces with high potency against microbes, photoactive agents, such as benzophenone (BP), 4,4'-bis(dimethylamino) benzophenone (MK), 4,4'-dihydroxybenzophenone (DHBP) and methylene blue (MB), were incorporated into polyurethane-based coating solutions. The photoactive antimicrobial agent treated leather samples were characterized by SEM, color appearance, color fastness against abrasion, and antimicrobial tests. The optical properties of organic photosensitizers indicated that active UV absorbance ranges were different: BP (around 250 $\mathrm{nm}$ ), MK (around $360 \mathrm{~nm}$ ), DHBP (around $305 \mathrm{~nm}$ ) and MB (around $295 \mathrm{~nm} \& 570 \mathrm{~nm}-685 \mathrm{~nm}$ ). The intensity of the UV absorbance curve at the UVA light wavelength for the antimicrobial test showed the highest value with MK; subsequently, this was followed by MB, DHBP and BP in decreasing order. The treated-leather samples demonstrated excellent antibacterial activity under UVA light. The antimicrobial effects for the Staphylococcus aureus were superior to Escherichia coli. Moreover, the polyurethane finishing showed an effective durability to abrasion. The overall results indicated that DHBP is the most suitable PU coating additive to provide antimicrobial properties to leather as well as color and surface appearance than $\mathrm{MK}, \mathrm{MB}$, and $\mathrm{BP}$.
\end{abstract}

Key words: organic photosensitizer, antimicrobial coating, benzophenone derivative, leather finishing, polyurethane

\section{Introduction}

Protection from hazardous materials is emerging as an important social issue since toxic substances and infectious bacteria threaten human health and the environment(Singh et al., 2001; Kenawy et al., 2007; Sun \& Dave, 2005). The most commonly used antimicrobial agents are titanium dioxide(Kwon et al., 2003; Li et al., 2009; Tryba, 2008), halamine compounds(Sun \& Sun, 2003), and quaternary ammonium(Tashiro, 2001). They are usually attached to the surfaces of substance and released slowly so that they can directly react with germs. Recently, among various antimicrobial agents, photoactive antimicrobial research has attracted increased attention as a clean technology(Mills \& Hunte, 1997). The chromophoric group of organic photosensitizers such as benzophenone are commonly used as photosensitizers. The carbonyl group of benzophenone generates free radicals through UV irradiation. The triplet structure can be easily quenched with oxygen; in addition, it extracts a hydrogen atom from any active hydrogen sources to form a ketyl radical. Harmful materials in contact with the ketyl group are oxidized and destroyed(Hong \& Sun, 2009; Hong \&

$\dagger$ Corresponding author; Kyung Wha Oh

Tel. +82-2-820-5381, Fax. +82-2-826-4243

E-mail: kwhaoh@cau.ac.kr
Sun, 2007). Our previous study(Lim \& Oh, 2011; Lim et al., 2012) found that polymers containing organic photosensitizers provided good antimicrobial properties. Photoactivity and mechanical properties of film containing various photosensitizers were significantly affected by type, the amount of photosensitizer, and contact areas.

Leather has various properties such as durability, elasticity, plasticity, resistance to perspiration, slipperiness and stiffness (Sundar et al., 2006). Generally leather goods were produced by a series of successive preparation processes such as pre-tanning operations to clean the hides or skins, tanning to permanently stabilize the leather, and finishing operation to protect the leather surface and give more favorable tactile touch. The tactile sensation of leather is related to the comfort, style, and appearance of clothing. The fabric hand is closely related to consumer needs demanded by the market. Therefore, several finishing techniques and coating materials have been continuously developed since final finishing process give significant effect on consumer preference. Among many coating materials, polyurethane(PU) dispersions are the most popular coating materials in leather finishing due to their excellent properties against abrasion and chemicals(Hong \& Sun, 2010). In additions, in order to improve the functionality of leather in various aspects, some functional additives were applied to the surface of leather during the finishing process, the final leather products 
would have desired functions on the surface.

In this study, leathers containing organic photosensitizers by coating method were investigated to demonstrate antimicrobial properties through the application of the material protective clothing and home furnishing. Photosensitizers such as benzophenone(BP), 4,4'-bis(dimethylamino) benzophenone(MK), 4,4'-dihydroxybenzophenone(DHBP) and methylene blue(MB) were used by selecting materials. The materials were dissolved with 1-propanol and distilled water in order to measure UV/V is absorbance. The morphology of the leather were confirmed by Scanning Electron Microscope(SEM) and the color change of materials was detected with CIE $\mathrm{L}^{*} \mathrm{a}^{*} \mathrm{~b}^{*}$ colorimetric system. Finally, an antimicrobial test(JIS Z 2801) was utilized to evaluate the antimicrobial activity of the leather.

\section{Experimental}

\subsection{Materials}

Organic photosensitizers(PS) such as benzophenone(BP, 99\% pure), 4,4'-bis(dimethylamino) benzophenone(MK, 98\% pure) and 4,4'-dihydroxybenzophenone(DHBP, 99\% pure) and methylene blue(MB) were used after purchase from Sigma-Aldrich Co. (Fig. 1). 1-propanol (99.5\%, Cas no. 71-23-8) (a solvent of organic photosensiters) was purchased from Junsei Chemical Co. Leather (grade c) and PU-based solution were purchased from SamangTongsang Co.. PU-based solution was made up some materials such as silicon wax, polyurethane and union compact binder.

\subsection{Preparation}

Unfinished leather was cut into $30 \times 30 \mathrm{~cm}^{2}$ and the surfaces were cleaned by air compression. PS and PU-based solutions were prepared by in Table 1. After pre-experiment, optimum concentration of $1.5 \mathrm{wt} \%$ PS were added to the PU-based solution. The PU-based solutions with/without PS were coated to the surface of the unfinished leathers by spray method in an approximate amount of $5.0 \mathrm{~g}$

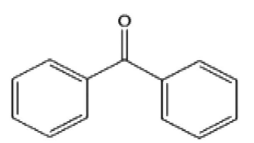

(a)

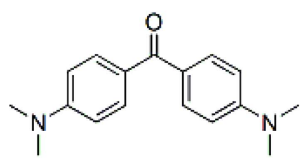

(c)

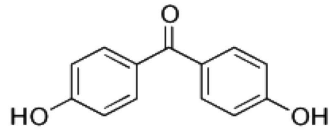

(b)

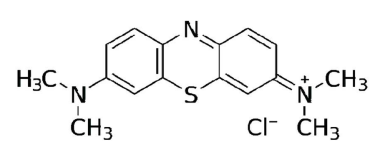

(d)
Fig. 1. Chemical structures of photosensitizers; BP(a), DHBP(b), MK(c), and $\mathrm{MB}(\mathrm{d})$.
Table 1. Preparation of PU solution containing the organic photosensitizers

\begin{tabular}{lccccc}
\hline & \multicolumn{5}{c}{ Formulation of leather coating solutions } \\
\cline { 2 - 6 } & Control & BP & MK & DHBP & MB \\
\hline PU-based coating solution (g) & 20.0 & 19.8 & 19.8 & 19.8 & 19.8 \\
PS/n-propanol (g) & - & 0.2 & 0.2 & 0.2 & 0.2 \\
n-propanol(g) & - & 0.197 & 0.197 & 0.197 & 0.197 \\
PS (g) & - & 0.003 & 0.003 & 0.003 & 0.003 \\
\hline
\end{tabular}

per $900 \mathrm{~cm}^{2}$. The coated leathers were placed in roller convection oven at $80^{\circ} \mathrm{C}$ for $40 \mathrm{sec}$. Then the leathers were dried in atmospheric condition for 24 hours.

\subsection{Characterization}

The UV/V is absorbance of each material was measured with a $\mathrm{UV} / \mathrm{V}$ is spectrometer(Scinco Co., S-4100, Korea) that ranged from $200 \mathrm{~nm}$ to $800 \mathrm{~nm}$. The morphology of the leather was measured with field-emission scanning electron microscopy(JEOL, JSM-6701F). The color measurements of the leathers containing organic photosensitizers were examined with a color spectrophotometer(Scinco Co., color mate). Color changes of the leathers according to each photosensitizer were reported with a CIE L*a*b* colorimetric system. Reference illuminant was D65(standard daylight) and observer angle was Diffuse $/ 10^{\circ}$ (illumination/measurement). The wavelength ranged from $400 \mathrm{~nm}$ to $700 \mathrm{~nm}$. An average value was taken from the 5-measurements. The color fastness to crocking of the leather was confirmed to the tendency of colorants to migrate from a test material as a result of rubbing by AATCC 8.

Lastly, Antimicrobial properties of the PS coated leather were measured against Staphylococcus aureus (ATCC 6538P) and Escherichia coli(ATCC 8739) according to the method of contact film(JIS Z 2801). The initial microbe ranged from $2.1 \times 10^{5}$ to $2.5 \times 10^{5}$ and added to PS coated leather $(5 \times 5 \mathrm{~cm})$ in a Petri dish. After dropping the $0.2 \mathrm{ml}$ diluted microbial solution, the solution was spread evenly on PS coated leather; in addition, UVA light were irradiated on the PS coated leather for 1, 2 and 3 hours, respectively.

Next, the PS coated leathers were immersed in a $20 \mathrm{ml}$ quenching solution (distilled water) and $1 \mathrm{ml}$ of the solution was put in a test tube with a $9 \mathrm{ml}$ saline solution in order to dilute the microbes. Then $1 \mathrm{ml}$ of the diluted microbial solution was taken by micropipette and poured in new Petri dish with a growth medium. The bacteria were incubated at $37^{\circ} \mathrm{C}$ for 24 hours and the bacteria means were measured by a colony counter.

Antimicrobial activity $(\mathrm{S})=\log \frac{\mathrm{Mb}}{\mathrm{Mc}}$ 
Degree of reduction $(\%)=\frac{\mathrm{Mb}-\mathrm{Mc}}{\mathrm{Mb}} \times 100$

(Ma: average number of bacteria in reference sample immediately after vaccination of testing bacteria

$\mathrm{Mb}$ : average number of bacteria in reference sample after incubation for 24 hours

Mc: average number of bacteria in antimicrobial sample after incubation for 24 hours)

Ma is the value as average number of bacteria in reference sample immediately after the vaccination of testing bacteria and is a standard to confirm activity change in comparison with $\mathrm{Mb}$ as average bacteria number in reference sample after incubation for 24 hours. If the value of $\mathrm{Ma}$ is lower than that of $\mathrm{Mb}$, the measurement of sample is confirmed to fail by nature reduction due to the external environment. The equations of antimicrobial activity (S) and degree of reduction (\%) are a system to measure in comparison with reference and antimicrobial samples after incubation for 24 hours; however, Ma is not used in the equation and is only included as a point of reference for the test.

\section{Results and Discussion}

\subsection{Optical properties of organic photosensitizers}

The UV/V is spectra of BP, MK, DHBP and MB selected as organic photosensitizers is shown in Fig. 1. The materials were dissolved in an1-propanol to measure the light absorbance that ranged from $200 \mathrm{~nm}$ to $800 \mathrm{~nm}$. Absorbance peak wavelength and intensities of BP (around $250 \mathrm{~nm}$ ), MK (360 nm), DHBP (305 nm) and MB (295 nm, 570-685 nm) were observed. The intensity of the UV absorbance at the wavelength of UVA (315-400 nm) light used for the antimicrobial test showed the highest value with MK; this was

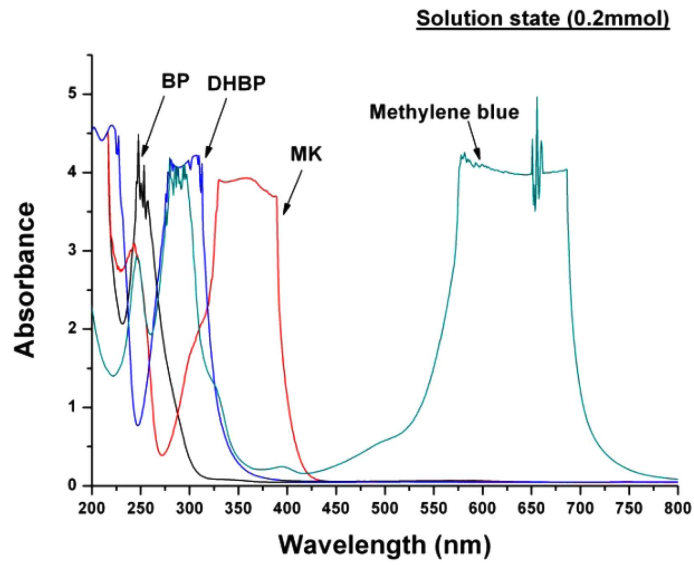

Fig. 2. UV/V is spectra of photosensitizer; $B P, M K, D H B P$ and $M B$ in solvent (1-propanol at a concentration of $0.2 \mathrm{mmol}$ ).
Table 2. CIE L*, $a^{*}, b^{*}$ colorimetric system of pristine leather and leather containing photosensitizers; BP, MK, DHBP, and MB

\begin{tabular}{lcccc}
\hline & $\mathrm{L}^{*}$ & $\mathrm{a}^{*}$ & $\mathrm{~b}^{*}$ & $\Delta \mathrm{E}$ \\
\hline Control & 59.361 & 4.128 & 18.709 & 0 \\
BP_1.5 wt\% & 60.186 & 4.250 & 18.439 & 0.885 \\
MK_1.5 wt\% & 59.776 & 3.217 & 19.183 & 1.168 \\
DHBP_1.5 wt\% & 61.190 & 3.837 & 18.759 & 1.857 \\
MB_1.5 wt\% & 25.665 & 5.715 & -24.864 & 55.106 \\
\hline
\end{tabular}

followed by DHBP, MB and BP in decreasing order. This greater intensity of UVA absorbance peaks for MK, DHBP, and MB than that of benzophenone (Fig. 2) demonstrates hyperchromic effect of substituents.

\subsection{Surface morphology and color appearance}

The color change of the leather that contains organic photosensitizer is presented in Table 2. The lightness ( $\left.\mathrm{L}^{*}\right)$ of the leather containing BP, DHBP and MK shows similar higher values than the pristine leather; however, the lightness of MB is darker than other materials because of blue coloring. The $\mathrm{a}^{*}$ value of all materials except DHBP is higher than that of pristine leather (target) and then shows indicate a dark redish color. Also the $b^{*}$ value of MB shows lowest negative value along the materials. The leather containing MB has the dark bluish color. Therefore the color of the leather is associated with wavelength of the UV/V is spectra.

Fig. 3 shows the morphologies of the control leather (only PUcoated) and sample leathers that contain various organic photo-

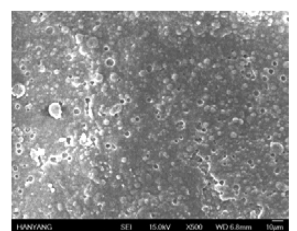

(a)

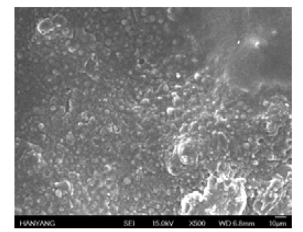

(c)

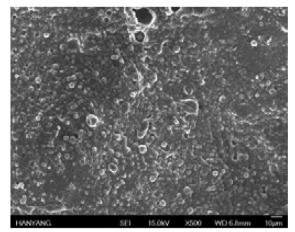

(e)

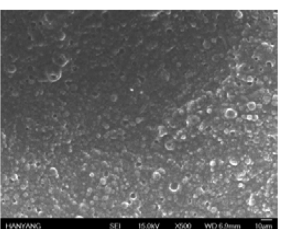

(b)

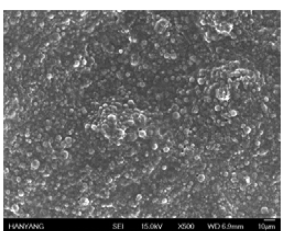

(d)
Fig. 3. Surface morphologies of control(a) and the leathers that contain photosensitizers; $\mathrm{BP}(\mathrm{b}), \mathrm{MK}(\mathrm{c}), \operatorname{DHBP}(\mathrm{d})$, and $\mathrm{MB}(\mathrm{e})$. 
Table 3. Color fastness to crocking of the leathers that contain photosensitizers; BP, MK, DHBP and MB

\begin{tabular}{lcc}
\hline & \multicolumn{2}{c}{ Colorfastness } \\
\cline { 2 - 3 } & DRY & WET \\
\hline Control & 5 & 5 \\
BP_1.5 wt $\%$ & 5 & 5 \\
DHBP_1.5 wt $\%$ & 5 & 5 \\
MK_1.5 wt $\%$ & 2.5 & 3 \\
MB_1.5 wt $\%$ & 1.5 & 1 \\
\hline
\end{tabular}

sensitizers. It was found that the surface of leathers containing organic photosensitizers became uniform and non-porous nearly. Also it confirmed that organic photosensitizers were distributed evenly on the leather.

The color fastness to crocking of the leather that contains organic photosensitizer is presented in Table 3 . The system was measured as dry and wet methods and used by 9 step chromatic transference scale from AATCC in order to evaluate. The photosensitizers such as BP and DHBP didn't transfer color to the white test cloth by both dry and wet crocking. However photosensitizers such as MK and MB showed that they couldn't be adhered to the leather completely, resulting in color change by abrasion.

\subsection{Antimicrobial properties}

Antimicrobial properties of leathers that contain various photosensitizers were evaluated and the results presented in Table 4. It was found that antimicrobial properties of the leathers that contain organic photosensitizers are superior to pristine leather by irradiating UVA light. Most likely, biological agents and toxic materials serve as sources of active hydrogen that result in an antimicrobial effect; subsequently, the materials containing a photosensitizer would be easily excited to the radicals that can decompose bacteria when activated by UV light. The carbonyl group in photosensitizer generates a free radical in the triplet state by UV irradiation and the ketyl group attracts $\mathrm{H}$ atoms to form suitable hydrogen donors. The antimicrobial effects for the Staphylococcus aureus were superior to those of Escherichia coli. For 2 hours UV irradiation, UV activated photosensitizers and provided superior antimicrobial properties to leather containing antimicrobial photosensitizers. The overall results indicated that MK, MB and DHBP

Table 4. Antimicrobial test results of the leather that contain various photosensitizers $(1.5$ wt $\%)$ with UVA irradiation for 2 hours

\begin{tabular}{|c|c|c|c|c|c|c|}
\hline \multicolumn{7}{|c|}{ Staphylococcus aureus } \\
\hline & & Ma & $\mathrm{Mb}$ & Mc & Antimicrobial activity (S) & Reduction (\%) \\
\hline \multirow{5}{*}{$\begin{array}{l}\text { No } \\
\text { UV }\end{array}$} & Control & $2.1 \times 10^{5}$ & $2.4 \times 10^{5}$ & $6.4 \times 10^{4}$ & 0.6 & 73.6 \\
\hline & BP_1.5 wt $\%$ & $2.1 \times 10^{5}$ & $2.4 \times 10^{5}$ & $4.2 \times 10^{4}$ & 0.8 & 82.6 \\
\hline & DHBP_1.5 wt $\%$ & $2.1 \times 10^{5}$ & $2.4 \times 10^{5}$ & $4.1 \times 10^{4}$ & 0.8 & 83.3 \\
\hline & MK_1.5 wt $\%$ & $2.1 \times 10^{5}$ & $2.4 \times 10^{5}$ & $1.3 \times 10^{4}$ & 1.3 & 94.6 \\
\hline & MB_1.5 wt $\%$ & $2.1 \times 10^{5}$ & $2.4 \times 10^{5}$ & $2.8 \times 10^{4}$ & 0.9 & 88.6 \\
\hline \multirow{5}{*}{$\begin{array}{l}\text { UV } \\
(2 \mathrm{~h})\end{array}$} & Control & $2.3 \times 10^{5}$ & $2.8 \times 10^{5}$ & $2.1 \times 10^{4}$ & 1.1 & 92.6 \\
\hline & BP_1.5 wt $\%$ & $2.3 \times 10^{5}$ & $2.8 \times 10^{5}$ & $<10$ & 4.5 & 99.9 \\
\hline & DHBP_1.5 wt $\%$ & $2.3 \times 10^{5}$ & $2.8 \times 10^{5}$ & $<10$ & 4.5 & 99.9 \\
\hline & MK_1.5 wt $\%$ & $2.3 \times 10^{5}$ & $2.8 \times 10^{5}$ & $<10$ & 4.5 & 99.9 \\
\hline & MB_1.5 wt $\%$ & $2.3 \times 10^{5}$ & $2.8 \times 10^{5}$ & $<10$ & 4.5 & 99.9 \\
\hline \multicolumn{7}{|c|}{ Escherichia coli } \\
\hline & & $\mathrm{Ma}$ & $\mathrm{Mb}$ & $\mathrm{Mc}$ & Antimicrobial activity (S) & Reduction (\%) \\
\hline \multirow{5}{*}{$\begin{array}{l}\text { No } \\
\text { UV }\end{array}$} & Control & $2.5 \times 10^{5}$ & $2.7 \times 10^{5}$ & $7.2 \times 10^{4}$ & 0.6 & 73.6 \\
\hline & BP_1.5 wt $\%$ & $2.5 \times 10^{5}$ & $2.7 \times 10^{5}$ & $5.9 \times 10^{4}$ & 0.7 & 78.1 \\
\hline & DHBP_1.5 wt $\%$ & $2.5 \times 10^{5}$ & $2.7 \times 10^{5}$ & $5.1 \times 10^{4}$ & 0.6 & 81.3 \\
\hline & MK_1.5 wt $\%$ & $2.5 \times 10^{5}$ & $2.7 \times 10^{5}$ & $3.2 \times 10^{4}$ & 0.9 & 88.2 \\
\hline & MB_1.5 wt $\%$ & $2.5 \times 10^{5}$ & $2.7 \times 10^{5}$ & $5.6 \times 10^{4}$ & 0.7 & 79.1 \\
\hline \multirow{5}{*}{$\begin{array}{l}\text { UV } \\
(2 \mathrm{~h})\end{array}$} & Control & $2.1 \times 10^{5}$ & $2.8 \times 10^{5}$ & $3.2 \times 10^{4}$ & 0.9 & 88.6 \\
\hline & BP_1.5 wt $\%$ & $2.1 \times 10^{5}$ & $2.8 \times 10^{5}$ & $<10$ & 4.5 & 99.9 \\
\hline & DHBP_1.5 wt $\%$ & $2.1 \times 10^{5}$ & $2.8 \times 10^{5}$ & $<10$ & 4.5 & 99.9 \\
\hline & MK_1.5 wt $\%$ & $2.1 \times 10^{5}$ & $2.8 \times 10^{5}$ & $<10$ & 4.5 & 99.9 \\
\hline & MB $1.5 w t \%$ & $2.1 \times 10^{5}$ & $2.8 \times 10^{5}$ & $<10$ & 4.5 & 99.9 \\
\hline
\end{tabular}

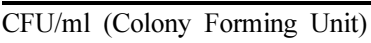


provided superior antimicrobial properties to benzophenone.

\section{Conclusion}

Self-decontamination materials were developed with organic photosensitizers in this study. Four photosensitizers with the excellent photoactive efficiency were coated on leather with PU-based solution. The optical properties of organic photosensitizers indicated that active UV absorbance ranges were different; BP (around $250 \mathrm{~nm}$ ), MK (around $360 \mathrm{~nm}$ ), DHBP (around $305 \mathrm{~nm}$ ) and MB (around $295 \mathrm{~nm} \& 570 \mathrm{~nm}-685 \mathrm{~nm}$ ). The intensity of the UV absorbance curve at the wavelength of UVA light used for the antimicrobial test showed the highest value with MK; this was followed by MB, DHBP and BP in decreasing order. The lightness $\left(\mathrm{L}^{*}\right)$ of the leather containing BP, DHBP and MK shows similar higher values than the control leather; however, the lightness of $\mathrm{MB}$ is darker than other materials because of the dye. The surface of leathers containing organic photosensitizers became uniform and non-porous nearly. The BP and DHBP didn't transfer color to the white test cloth by both dry and wet crocking, whereas, MK and MB didn't. Antimicrobial properties of the leathers that contain organic photosensitizers are superior to control leather. The overall results indicated that DHBP is the most suitable PU coating additive to provide antimicrobial properties to leather as well as color and surface appearance than MK, MB, and BP. The coated leathers that contain effective photosensitizers have a strong potential to protect human health from pollutants and bacteria through the application to various fields such as clothing, bag, shoes and industrial materials.

\section{Acknowledgements}

This research was supported by Basic Science Research Program through the National Research Foundation of Korea (NRF) funded by the Ministry of Education, Science and Technology (Project No. 2012-047656).

\section{References}

Hong, K. H., \& Sun, G. (2007). Preparation and properties of electrospunpoly(vinyl alcohol)/silver fiber web as wound dressings.
Polymer Engineering and Science, 47, 1750-1755.

Hong, K. H., \& Sun, G. (2009). Photoinduced antimicrobial polymer blends with benzophenone as a functional additive. Journal of Applied Polymer Science, 112, 2019-2026.

Hong, K. H., \& Sun, G. (2010). Photoactive antimicrobial agents/ polyurethane finished leather. Journal of Applied Polymer Science, 115, 1138-1144.

Kenawy, E. R., Worley, S. D., \& Broughton, R. (2007). The chemistry and applications of antimicrobial polymers. Biomacromolecules, 8, 1359-1384.

Kwon, O. K., Moon, J. G., Son, B. H., \& Choi, Y. H. (2003). The functional properties of cellulose fabric treated with $\mathrm{TiO}_{2}$. Journal of the Korean Society for Clothing Industry, 5, 395-398.

Li, H., Zhang, Y., Wang, S., Wu, Q., \& Liu, C. (2009). Study on nanomagnets supported $\mathrm{TiO}_{2}$ photocatalysts prepared by a sol-gel process in reverse microemulsion combining with solvent-thermal technique. Journal of Hazardous Materials, 169, 1045-1053.

Lim, K. S., \& Oh, K. W. (2011). Photoactive and antimicrobial properties of PVA films containing various organic photoactivators. Textile Science and Engineering, 48, 42-50.

Lim, K. S., Oh, K.W., \& Kim, S. H. (2012). Antimicrobial activity of organic photosensitizers embedded in electrospun Nylon 6 nanofibers. Poly International, 61, 1519-1524.

Mills, A., \& Hunte, S. L. (1997). An overview of semiconductor photocatalysis. Journal of photochemistry and Photobiology A: Chemistry, 108, 1-35.

Singh, A., Lee, Y. W., \& Dressick, W. J. (2001). Self-cleaning fabrics for decontamination of organophosphous pesticides and related chemical agents. Advanced Materials, 16, 2112-2115.

Sun, G, \& Dave, W. S. (2005). Chemistry of durable and regenerablebiocidal textiles. Journal of Chemical Education, 82, 60-64.

Sun, Y., \& Sun, G. (2003). Novel refreshable N-halamine polymeric biocides: Grafting hydantoin-containing monomers onto high performance fibers by a continuous process. Journal of Applied PolymerScience, 88, 1032-1039.

Sundar, S., Vijayalakshmi, N., Gupta, S., Rajaram, R., \& Radhakrishnan, G. (2006). Aqueous dispersions of polyurethane-polyvinyl pyridine cationomers and their application as binder in base coat for leather finishing. Progress in Organic Coating, 56, 178-184.

Tashiro, T. (2001). Antibacterial and bacterium adsorbing macromolecules. Macromolar Materials and Engineering, 286, 63-87.

Tryba, B. (2008). Immobilization of $\mathrm{TiO}_{2}$ and $\mathrm{Fe}-\mathrm{C}-\mathrm{TiO}_{2}$ photocatalysts on the cotton material for application in a flow photocatalytic reactor for decomposition of phenol in water. Journal of Hazard Materials, 151, 623-627.

(Received 21 May 2013; 1st Revised 29 May 2013; 2nd Revised 30 May 2013; Accepted 20 July 2013)

Copyright $(C$ The Society of Fashion and Textile Industry. 2013. This is an open access article distributed under the terms and conditions of the Creative Commons Attribution Non-Commercial license (http://creativecommons.org/licenses/by-nc/3.0/), which permits unrestricted non-commercial use, distribution, and reproduction in any medium, provided the original work is properly cited. 